Article

\title{
Assessment of Wheat Straw Cover and Yield Performance in a Rice-Wheat Cropping System by Using Landsat Satellite Data
}

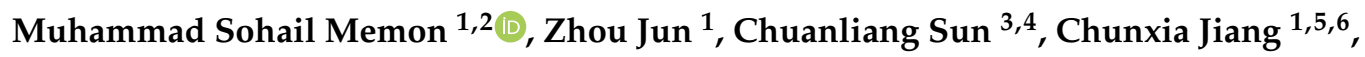 \\ Weiyue $\mathrm{Xu}^{1,7}$, Qiong $\mathrm{Hu}^{8}$, Hangxu Yang ${ }^{1,9}$ and Changying $\mathrm{Ji}^{1, *}$ \\ 1 College of Engineering, Nanjing Agricultural University, Nanjing 210031, China; \\ engr.sohailm@yahoo.com (M.S.M.); zhoujun@njau.edu.cn (Z.J.); chunxia_njau@163.com (C.J.); \\ wyxu_1990@126.com (W.X.); yanghx_83@126.com (H.Y.) \\ 2 Faculty of Agricultural Engineering, Sindh Agriculture University, Tandojam 70060, Pakistan \\ 3 Institute of Agricultural Information, Jiangsu Academy of Agricultural Sciences, Nanjing 210014, China; \\ chuanlia@ualberta.ca \\ 4 Department of Earth and Atmospheric Sciences, Faculty of Science, University of Alberta, \\ Edmonton, AB T6G 2E3, Canada \\ 5 College of Mechanical Engineering, Anhui Science and Technology University, \\ Chuzhou City 233100, Anhui, China \\ 6 Department of Biological and Agricultural Engineering, University of California Davis, \\ Davis, CA 95616, USA \\ 7 Department of Biological and Agricultural Engineering, College of Engineering, Texas A\&M University, \\ Texas, TX 77843-1255, USA \\ 8 Key Laboratory for Geographical Process Analysis \& Simulation Hubei Province/School of Urban and \\ Environment Sciences, Central China Normal University, Wuhan 430079, China; huqiong@mail.ccnu.edu.cn \\ 9 College of Mechanical and Electrical Engineering, Jinhua Polytechnic, Jinhua 321017, China \\ * Correspondence: chyji_njau@outlook.com or chyji@njau.edu.cn; Tel.: +86-25-5860-6571
}

Received: 7 July 2019; Accepted: 18 September 2019; Published: 28 September 2019

\begin{abstract}
Proper straw cover information is one of the most important inputs for agroecosystem and environmental modeling, but the availability of accurate information remains limited. However, several remote-sensing (RS)-based studies have provided a residue cover estimation and provided spatial distribution mapping of paddy rice areas in a constant field condition. Despite this, the performance of rice crops with straw applications has received little attention. Furthermore, there are no methods currently available to quantify the wheat straw cover (WSC) percentage and its effect on rice crops in the rice-wheat cropping region on a large scale and a continuous basis. The novel approach proposed in this study demonstrates that the Landsat satellite data and seven RS-based indices, e.g., (i) normalized difference vegetation index (NDVI), (ii) Normalized difference senescent vegetation index (NDSVI), (iii) Normalized difference index 5 (NDI5), (iv) Normalized difference index 7 (NDI7), (v) Simple tillage index (STI), (vi) Normalized difference tillage index (NDTI), and (vii) Shortwave red normalized difference index (SRNDI), can be used to estimate the WSC percentage and determine the performance of rice crops over the study area in Changshu county, China. The regression model shows that the NDTI index performed better in differentiating the WSC at sampling points with a coefficient of determination $\left(R^{2}=0.80\right)$ and root mean squared difference (RMSD $=8.46 \%$ ) compared to that of other indices, whereas the overall accuracy for mapping WSC was observed to be $84.61 \%$ and the kappa coefficient was $k=0.76$. Moreover, the rice yield model was established by correlating between the peak NDVI values and rice grain yield collected from ground census data, with $R^{2}=0.85$. The finding also revealed that the highest estimated yield $(8439.67 \mathrm{~kg} / \mathrm{ha})$ was recorded with $68 \%$ WCS in the study region. This study confirmed that the NDVI and NDTI algorithms are very effective and robust indicators. Also, it can be strongly concluded that multispectral Landsat satellite imagery is capable of measuring the WSC percentage and successively determines the impact
\end{abstract}


of different WSC percentages on rice crop yield within fields or across large regions through remote sensing (RS) and geographical information system (GIS) techniques for the long-term planning of agriculture sustainability in rice-wheat cropping systems.

Keywords: agricultural sustainability; remote sensing; Landsat; crop yield; GIS; spatial analysis; wheat straw cover percentage; vegetation indices

\section{Introduction}

Soil is a main natural resource, and its quality provides an integrated impact for management involving most soil properties that assess crop yield and sustainability [1]. However, agricultural sustainability is related to soil quality, which is defined as the ability of a particular kind of soil to work within natural or managed boundaries. Soil simultaneously achieves higher crop yield and incomes (food security), enhanced resilience to climate change (adaptation), and reduction of greenhouse gas emissions (mitigation) through different climate-smart agriculture (SMA) techniques [2], such as stone bunds, zaii, and the half-moon method combined with the application of crop straw incorporation/retention [3], organic or mineral fertilizers, which increased agricultural productivity, and carbon sequestration [4]. Additionally, crop straw is imperative for reduced soil degradation and carbon depletion, which are intensified by soil mismanagement $[5,6]$. The retention of crop residue/straw is considerable and can play an important role in improving crop yield [3,7] and increasing soil carbon storage $[8,9]$. Conservation agriculture (CA), as explained by the Conservation Technology Information Center CTIC [10], is defined as the tillage intensity of the amount of crop straw cover that remains on the soil surface shortly after planting. Conservation has $>30 \%$ residue cover, Reduced-till has $15-30 \%$, and Intensive/conventional tillage provides $0-15 \%$ residue cover on soil surface following planting [11]. Furthermore, an accurate estimation of the percent of crop residue cover is a critical parameter to use for input into soil models [12]. In addition, agroecosystem models have been developed for evaluating carbon $(C)$ sequestration associated with various crops and soil management practices, including the adoption of appropriate tillage methods with crop straw retained to prevent soil loss [13-15].

For the proper management of a straw application for higher crop production, it is essential to calculate crop straw cover (CSC) in a vast agricultural region. However, the traditional survey-based approaches, including visual estimation [16], line transect, meter stick [17,18], spiked wheel [19], and the photographic techniques [20] are time-consuming methods. However, a regional survey of the conservation tillage method based on annual road-side assessments of crop residue levels after planting [10] is compiled for selected counties by Daughtry et al. [21]. These studies focus on straw estimation, and their methods vary from county to county [22]. Unfortunately, these traditional methods for quantifying CSC over large regions are unsuitable, expensive, and time-consuming; likewise, they are not well suited for large spatial coverage [23].

Moreover, some researchers use remote-sensing (RS) -and geographical information system (GIS) techniques to measure various amounts of CSC on a regional scale. Remote-sensing methods can provide a uniform approach for modeling the spatial variation in residue cover on a continuous surface over large areas. The soil and straw are visible in near-infrared spectral regions (350-2500 nm) with similar spectral characteristics. However, the crop straw only exists in the vicinity of $2100 \mathrm{~nm}$ cellulose and lignin absorption [24]. To effectively distinguish soil and straw, there are many robust crop residue indices and algorithm methods are used under the Hyperion images based on absorption according to the Cellulose Absorption Index (CAI) by Daughtry et al. [25]. Unfortunately, there are only a few hyperspectral satellite sensors, and their areal and temporal coverage is very limited.

In addition, several satellites with broadband multispectral sensors currently orbit the Earth and can provide frequent, wide-area coverage of agricultural lands. However, several soil tillage/crop residue indices have been developed with the various combinations of Landsat TM, ETM+, and 
OLI-TIRS multispectral bands [26-28]. These indices were based on relative differences in the broadband reflectance for soils and crop residues and were used to identify the ones that are more suitable for estimation of the CSC percentage [29,30].

Consequently, the correlations between the normalized difference tillage Index (NDTI), simple tillage index (STI), and CRC using bands five and seven of the Landsat-5 TM data demonstrate that strong relationships to the data are exhibited between these parameters [31]. Furthermore, the minimum NDTI (minNDTI) tillage index was used to estimate CSC $\left(R^{2}=0.89\right)$ based on a time series of Landsat TM and ETM+ data [32]. Wheat (Triticum aestivum L.) and rice (Oryza sativa) are the most important staple food crops produced in Jiangsu province, China, and planting areas for both crops account for one-fifth of the total crop area of the country [33-35]. The wheat straw cover (WSC) was left after harvesting at the end of May to June in a rice-wheat rotation field, while the rice crop was harvested in November-December in the study area.

In this context, some significant gaps in knowledge remain from previous studies. There is a need to describe the estimation of WSC on the surface regarding the performance of crop yield under different straw management systems throughout an agricultural area by using RS and GIS- based techniques. Many studies have used optical RS satellites, such as Moderate Resolution Imaging Spectroradiometer (MODIS), National Oceanic and Atmospheric Administration (NOAA), Landsat and SPOT data, to identify paddy rice fields [36,37]. Besides, some studies have been carried out to map paddy fields using the temporal profiles of Land Surface Water Index (LSWI) and normalized difference vegetation index (NDVI) data derived from MODIS and vegetation indices during the transplanting period in China $[38,39]$. A considerable amount of investigation has been completed with regards to RS application with satellite images for the monitoring and classification of rice crops, but little is known about the actual interactions of different straw cover percentage effects on crop performance using remote sensing [40]. Thus, there is a strong need to develop methods for the accurate estimation of crop straw over large areas, and cropping performance should be studied over time using consistent methods. The specific objectives of this study were (i) to estimate the wheat straw cover (WSC) and mapping the WSC percentage classification through different remote sensing (RS) as well as GIS-based tillage indices, and (ii) to evaluate the crop yield performance with different straw amounts by using Landsat ancillary data and RS methods in rice-wheat rotation fields.

\section{Materials and Methods}

\subsection{Study Region}

The study was conducted in different villages of Changshu county, which is located between $31^{\circ} 39^{\prime} 54^{\prime \prime}$ N, $120^{\circ} 49^{\prime} 19^{\prime \prime}$ E (Figure 1) with worldwide reference system (WRS) Path 119 and Row 38 under the jurisdiction of Suzhou District Jiangsu Province, China. This area is situated in the Tai Lake plain across the Yangtze River Delta, with a total area of $1276 \mathrm{~km}^{2}$, including $386 \mathrm{~km}^{2}$ occupied water area, and the total cultivable land making up 42,265 hectares, from which 27,451 hectares are paddy fields, and 9214 hectares are dry land. The study area is in a transition zone between the subtropical monsoon humid climatic region with recorded seasonal precipitation of $800-900 \mathrm{~mm}$ and an average annual temperature of $15.4^{\circ} \mathrm{C}$. The major cropping system of the study area is winter wheat and summer rice, while most of the soils in this area are loam and clay loam in texture. 


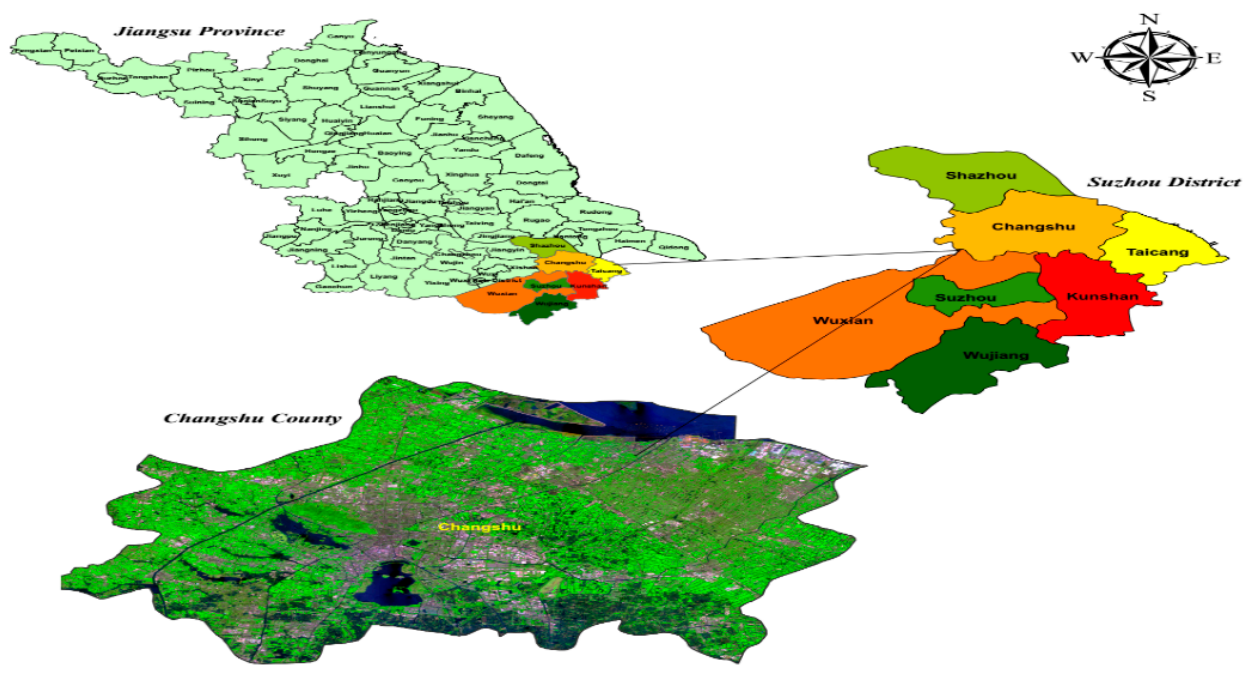

Figure 1. Location of Changshu County (true color band composite Landsat-8 OLI-TIRS); Red (Band4), Green (Band3), and Blue (Band2).

\subsection{Ground-Truth Field Study and Measurements}

A geo-referenced survey of different sites was conducted in Changshu County during May-June and November-December in 2017 with the help of a geographical map and GPS. The spatial distribution of the field data was collected from 40 selected sampling points (Figure 2), whereas, before a field visit, a proforma (Figure S1) was prepared for collecting the qualitative observations and the required information. The attribute proforma included coordinated prior crop yields, tillage methods, a straw incorporation method, and retaining amounts.

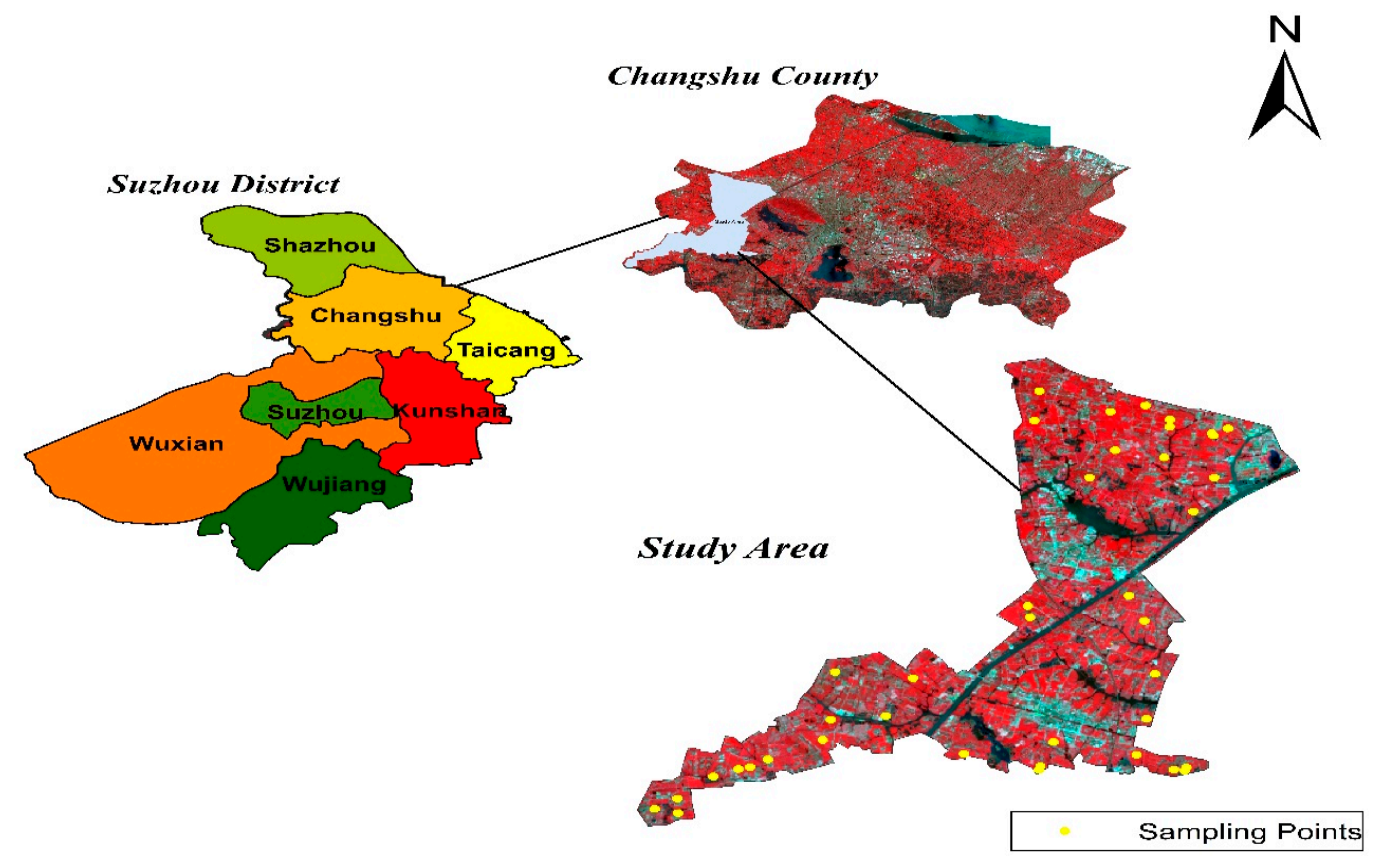

Figure 2. Location of the study area and sampling points (color infrared band composite Landsat-8 OLI-TIRS); Red (Band5), Green (Band4), and Blue (Band3).

The current study comprised both field data and preceding residues for the selected crop to ensure an accurate estimation of the straw cover percentage, which is utilized for the straw incorporation, and the performance of the crop yield was based on farmers' interviews and data collection (Figure 3). 

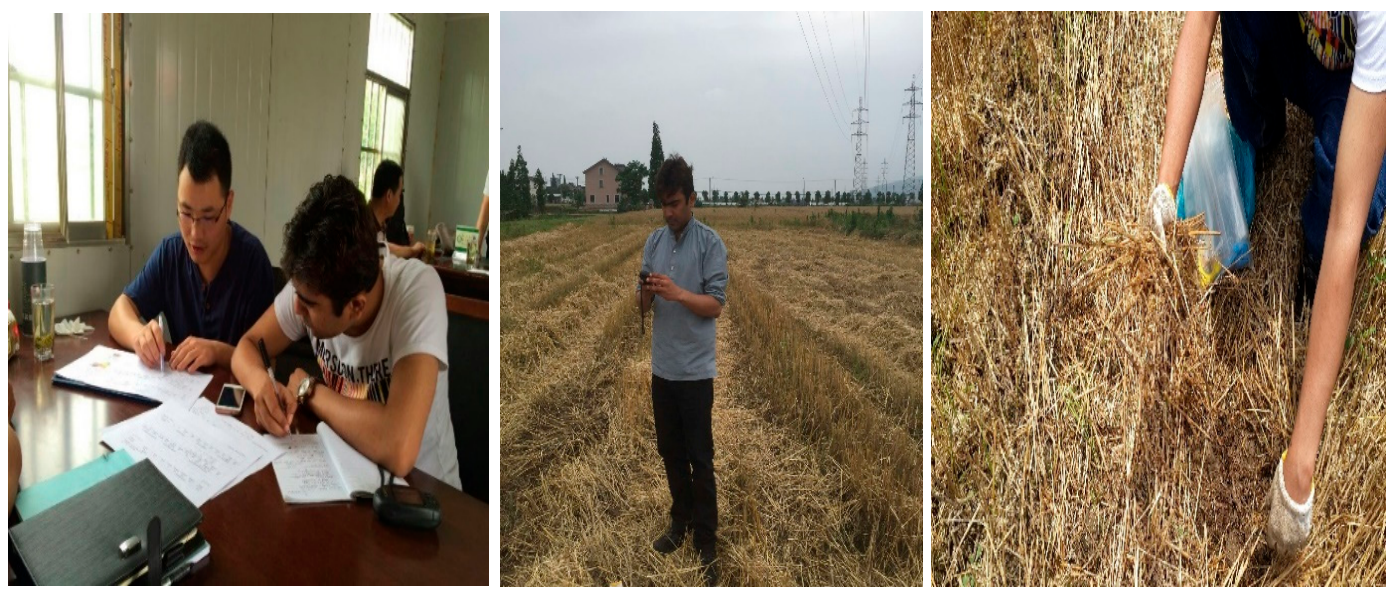

Figure 3. Collecting the required data and site location coordinates.

\subsection{Measurement of Straw Cover Percentage in an In Situ Condition}

The WSC at field sites were calculated using a line transect method [19] from 23 May to 2 June 2017 in 40 rice-wheat rotation fields, whereas the area of each sample plot was approximately $1425.36 \mathrm{~m}^{2}$ and was relatively homogeneous. At each test plot, we used a stretching measuring tape of $50 \mathrm{ft}$ $(15.24 \mathrm{~m})$ line-point transect (Figure S2), which could be easily distributed into 100 evenly spaced markers with $0.5 \mathrm{ft}$ intervals that were stretched diagonally across the rows [19,32]. The location of each farm site was recorded with a global positioning system (GPS) receiver.

\subsection{Measurement of Straw Cover Percentage in an In Situ Condition}

The Landsat EMT+ and OLI-TIRS multispectral satellite images (Collection 1 SR data) of the study area were downloaded from the United States Geological Survey (USGS) EarthExplorer platform available at (http://www.earthexplorer.usgs.gov). However, for the estimation of straw cover percentage, we selected images after the crop harvest and before the rice planted. Furthermore, satellite images relative to the peak cropping season (August-November) were acquired to detect the changes and determine the crop yield performance under different WSCs in the study region.

\subsection{Image Acquisition}

A total of nine images of different temporal resolutions for the study area were acquired from both of the satellite sensors, i.e., Landsat ETM+ and OLI-TIRS, from Mid-May to June 2017 for a straw cover estimation and July to November 2017 to assess crop performance. A summary of the satellite imagery used in this study is shown in Table 1.

Table 1. Summary of Landsat (7 and 8) imagery used in the study.

\begin{tabular}{ccccc}
\hline No. & Acquisition Dates & Sensor & DOY & Scene Cloud Cover \\
\hline 1 & 27 May 2017 & OLI-TIRS & 146 & 4.95 \\
2 & 4 June 2017 & ETM+ & 154 & 14.00 \\
3 & 14 July 2017 & OLI-TIRS & 194 & 11.02 \\
4 & 23 August 2017 & ETM+ & 234 & 16.12 \\
5 & 16 September 2017 & OLI-TIRS & 258 & 18.76 \\
6 & 10 October 2017 & ETM+ & 282 & 20.00 \\
7 & 3 November 2017 & OLI-TIRS & 306 & 12.55 \\
8 & 11 November 2017 & ETM+ & 314 & 6.00 \\
9 & 27 November 2017 & ETM+ & 330 & 3.00 \\
\hline
\end{tabular}

Note: Acquisition Dates, denoted as the image were acquired by the satellite; Sensor, the two different satellite sensors were used; DOY, shown as the "Day of Year" indicates when the image were taken by the satellite and Scene Cloud Cover; described as the percentage of cloud cover by the Satellite Scene in the study area. 


\subsection{Methods for Image Preprocessing}

All satellite images were queried and processed with different preprocessing methods, including radiometric calibration, geometric correction, and atmospheric correction [26], by using RS processing software ENVI 5.3.

\subsection{Analysis of Crop Residue and Vegetation Indices}

The processing used for the estimation of wheat straw cover percentage and the performance of rice crop in this study was encompassed by three different phases, the details and method of these phases are described as the following:

(i) Data preparation and extraction of vegetation indices (VI's) and crop residue indices (CRI's)

The full analyzation process workflow for data collection and extraction process in regards to VI's and CRI's was studied for each Landsat images under the study area by using ArcMap model builder tool (Figure S3). This tool was built with ArcMap software [40], and its objectives were to automate the process of the determined, different indices values for the satellite scene. The model illustrates the four primary processing methods, including: (a) Import of full Landsat scene, (b) Extraction of Band for Study area, (c) Analysis of VI's and CRI's, and (d) Extraction of results in an Excel Spreadsheet for further analysis. While creating this model, some inputs were set as parameters to enable the user to change them based on their region and information required. This process was accomplished by using the Extract by Mask tool in order to reduce the amount of disk space used and increase the speed during the processing time.

(ii) Spatial distribution of wheat straw cover and rice cropping fields

Several supervised or unsupervised methods were examined in literature for automatic straw cover measurement and crop classes; all of these methods have to overcome problems related to the data [41]. Approaches, which are object-oriented and combine multispectral data such as Landsat Satellite and Light Detection and Ranging (LIDAR) data, are even more useful in the reduction of these types of problems [42]. Consequently, in this phase the segmentation and classification procedures were performed on acquired unclassified satellite imagery of the study area with ArcMap software by creating signature files in regards to different WSC percentages on the basis of CRI's results, while the rice-growing cultivation areas were extracted by field survey data and then the maximum likelihood classification algorithm was applied to get classified maps under distinct categories. From the above procedure, shapefile (.shp) was created according to the data of straw cover percentages and rice cultivation areas. These shapefiles were used, with map algebra tools, to create the classified maps of the study area by using GPS positions which were obtained for each sampling point. The overall accuracy of the rice-cropping area was $86 \%$, which fulfilled the requirements of the current study. Similarly, the area coverage of different percentages of straw cover and rice cultivation was measured from the classified maps.

\section{(iii) Cropping performance under different WSC percentages}

There are many vegetation indices, such as NDVI, EVI (enhanced vegetation index) and SAVI (Soil-Adjusted Vegetation Index), which have been used to discriminate crops and monitor crop growth conditions $[43,44]$. Among these vegetation indices, the NDVI is the most widely used as compared to other indices. After rice areas were mapped, the performance of crop under the different percentage of WSC was determined by developing a crop yield regression-based model between peak NDVI and measured grain yield data. Subsequently, we applied the yield model to all the sampling points $(n=40)$ with respective NDVI values and compared the estimated crop yield. 
However, in the current study, the different remote-sensing-based vegetation and crop residue indices used for estimates of the straw cover and cropping performance are illustrated in Table 2. These formulae are different because the Landsat- 8 satellite bands have different wavelength values [45,46] compared to Landsat 7 ETM+ (Table S1).

Table 2. Selected remote-sensing-based vegetation indices for crop yield performance and percentage of straw cover estimation.

\begin{tabular}{|c|c|c|c|}
\hline Vegetation Index & OLI-TIRS & (ETM+) & Reference \\
\hline Simple tillage index (STI) & $\mathrm{B} 6 / \mathrm{B} 7$ & B5/B7 & [31] \\
\hline Normalized difference tillage index (NDTI) & $(\mathrm{B} 6-\mathrm{B} 7) /(\mathrm{B} 6+\mathrm{B} 7)$ & $(\mathrm{B} 5-\mathrm{B} 7) /(\mathrm{B} 5+\mathrm{B} 7)$ & {$[31]$} \\
\hline Normalized difference index 5 (NDI5) & $(\mathrm{B} 5-\mathrm{B} 6) /(\mathrm{B} 5+\mathrm{B} 6)$ & $(\mathrm{B} 4-\mathrm{B} 5) /(\mathrm{B} 4+\mathrm{B} 5)$ & [16] \\
\hline Normalized difference index 7 (NDI7) & $(\mathrm{B} 5-\mathrm{B} 7) /(\mathrm{B} 5+\mathrm{B} 7)$ & $(\mathrm{B} 4-\mathrm{B} 7) /(\mathrm{B} 4+\mathrm{B} 7)$ & [16] \\
\hline $\begin{array}{l}\text { Shortwave red normalized difference index } \\
\text { (SRNDI) }\end{array}$ & $(\mathrm{B} 7-\mathrm{B} 4) /(\mathrm{B} 7+\mathrm{B} 4)$ & $(\mathrm{B} 7-\mathrm{B} 3) /(\mathrm{B} 7+\mathrm{B} 4)$ & [26] \\
\hline $\begin{array}{c}\text { Normalized difference senescent vegetation } \\
\text { index (NDSAVI) }\end{array}$ & $(\mathrm{B} 6-\mathrm{B} 4) /(\mathrm{B} 6+\mathrm{B} 4)$ & $(\mathrm{B} 5-\mathrm{B} 3) /(\mathrm{B} 5+\mathrm{B} 4)$ & [28] \\
\hline Normalized difference vegetation index (NDVI) & $(\mathrm{B} 5-\mathrm{B} 4) /(\mathrm{B} 5+\mathrm{B} 4)$ & $(\mathrm{B} 4-\mathrm{B} 3) /(\mathrm{B} 4+\mathrm{B} 3)$ & [47] \\
\hline
\end{tabular}

\subsection{Modeling and Statistical Analysis}

The calculated WSC data were randomly divided into two datasets: a training or calibration dataset ( $65 \%$ of the total data), and a testing or validation dataset ( $35 \%$ of the total data). The training set is implemented to build up regression equation models. The models were then applied to a testing dataset to validate the model built and evaluate the consistency between the measured and predicted WSC (Figure 4). The statistics of each dataset for the estimates of wheat straw cover are depicted in Table 3.

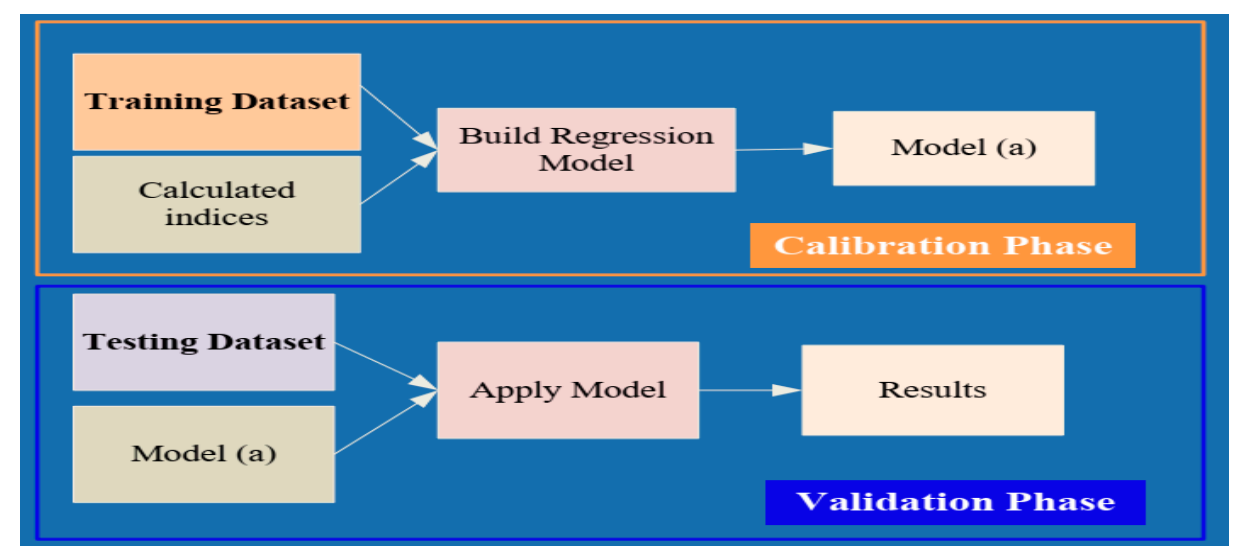

Figure 4. Process of training and the testing data for model building and validation.

Table 3. Data statistics of wheat straw cover (WSC) percentage in the study region.

\begin{tabular}{ccccccccc}
\hline Dataset & $\begin{array}{c}\text { Number of } \\
\text { Samples }\end{array}$ & Max & Min & Average & $\begin{array}{c}\text { Standard } \\
\text { Error }\end{array}$ & $\begin{array}{c}\text { Standard } \\
\text { Deviation }\end{array}$ & $\begin{array}{c}\text { Confidence } \\
\text { Level (95.0\%) }\end{array}$ & $\begin{array}{c}\text { Sample } \\
\text { Variance }\end{array}$ \\
\hline $\begin{array}{c}\text { Training dataset } \\
\begin{array}{c}(65 \%) \\
\text { Testing dataset } \\
(35 \%)\end{array}\end{array}$ & 26 & 96 & 30 & 64 & 3.16 & 16.36 & 6.75 & 267.71 \\
\hline
\end{tabular}


The model performance was evaluated through the root-mean-square deviation (RMSD) percentage between the predicted and the measured WRC. The RMSD is calculated by Equation (1). Moreover, the kappa coefficient $(\kappa)$ is a degree of the "true" agreement. The collected field survey and processed satellite imagery data were analyzed using SPSS software [48]. The RMSD and coefficient of determination $\left(R^{2}\right)$ values were used to evaluate the WSC and crop performance model, which were developed in this study.

$$
\operatorname{RMSD}=\sqrt{\frac{1}{n}(x-y)^{2}}
$$

where $\mathrm{n}$ is the number of recorded wheat straw cover (WRC) sampling points; $\mathrm{x}$ is the observed WRC values, and y is the predicted WRC.

\section{Results}

\subsection{Field Measurements}

Wheat straw cover (WSC) was measured with line-point transect methods from 40 rice-wheat rotational fields after the crop harvest. Generally, the study areas are mostly occupied with paddy fields, and the highest CSC recorded was $96 \%$, while the lowest cover was $\geq 30 \%$ at the sampling points.

\subsection{Model Performance of Landsat-Based Crop Residue Indices (CRIs) for Wheat Straw Cover}

The correlation between the crop residue indices (CRI) and wheat straw cover (WSC) based on simple linear regression and nonlinear regression models with coefficients of determination $\left(R^{2}\right)$ were developed as presented as in Figure 5. The calculated WSR sampling points using RS-based CRI for the training dataset $(n=26)$ of the study area were studied as well. Two satellite images were selected, e.g., 27 May 2017 and 4 June 2017, for the estimation of WSC.
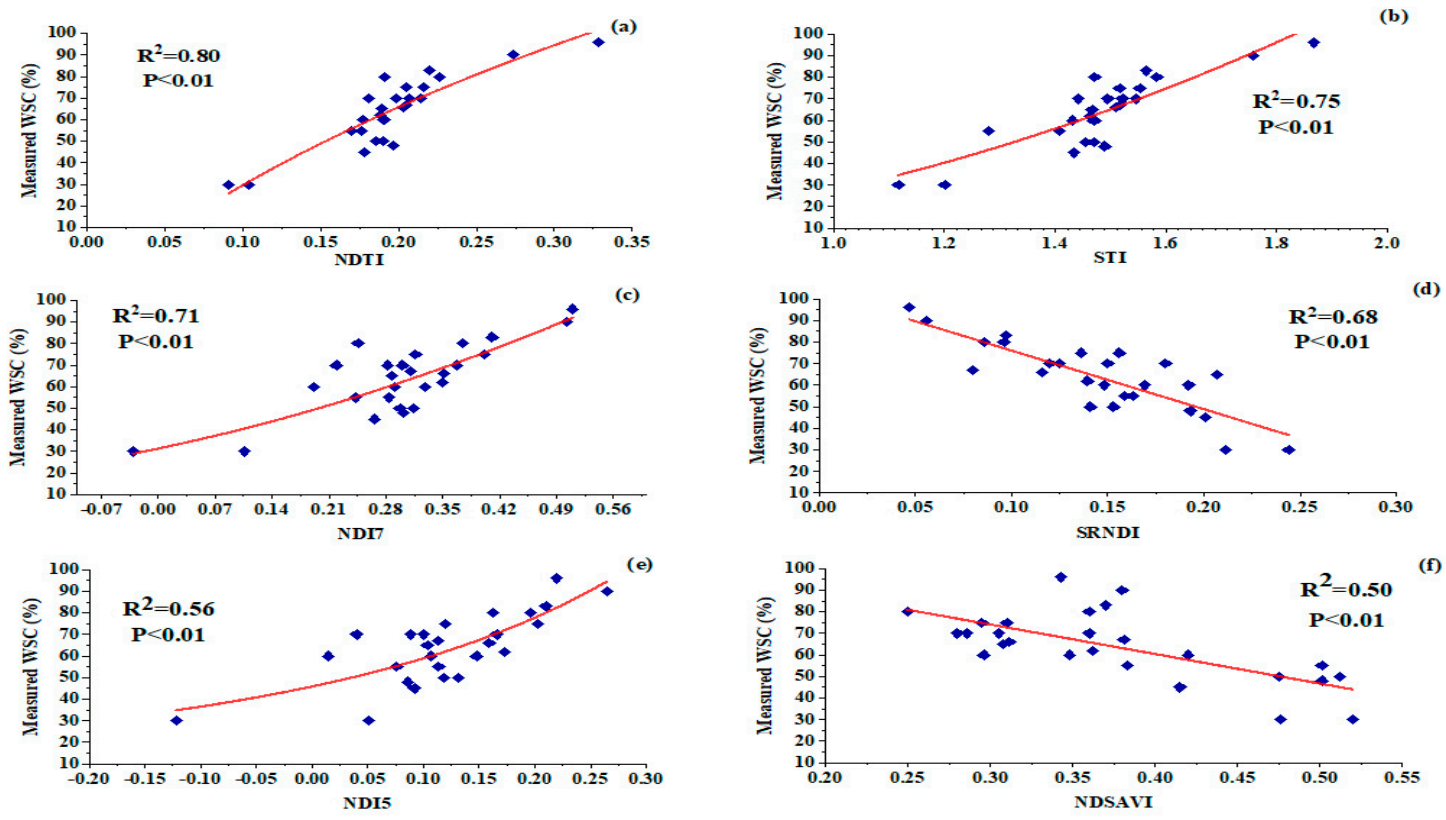

Figure 5. Shows the regression between measured wheat straw cover (WCR, \%) as a function of (a) NDTI, (b) STI, (c) NDI7, (d) SRNDI, (e) NDI5, and (f) NDSAVI for training dataset $(n=26)$. 
However, our study revealed that the NDTI, STI, NDI7, and NDI5 observed positive relationships between WSC and CRIs. At the same time, an inverse relationship for NDSVI and SRNDI was observed with WSC percentages. The highest and lowest $R^{2}$ values were found in NDTI and NDSAVI indices at 0.80 and 0.50 , respectively. The upper and lower values of $R^{2}$ in respect of WSC were in the order of NDTI, STI, NDI7, SRNDI, NDI5, and NDSAVI, as depicted in Table 4. Moreover, the RMSD values of CRIs in regards to model performance showed a discrete finding as compared to $R^{2}$ because the RMSD value indicated the prediction power of the estimation linear equations for WSC, while lower RMSD values showed that the estimation equation for WSC had better prediction accuracy. The RMSD values ranged from $8.46 \%$ to $20.79 \%$ for different crop residue indices (Table 4 ). These results for $R^{2}$ and RMSD were comprehensively considered to select the best fitting regression equation for assessing wheat straw cover percentage [26].

Table 4. Root mean square difference, coefficient of determination $\left(R^{2}\right)$ and models developed for all crop residue indices ( $n=60 \%$ of measured WSC sampling points).

\begin{tabular}{ccccc}
\hline Residue Index & $\mathbf{N}$ & $\boldsymbol{R}^{\mathbf{2}}$ & Regression Equation & RMSD (\%) \\
\hline NDSAVI & 26 & $0.50^{* *}$ & $y=158.62 e^{-2.519 x}$ & 20.79 \\
NDI5 & 26 & $0.56^{* *}$ & $y=44.094 e^{2.7874 x}$ & 18.53 \\
SRNDI & 26 & $0.68^{* *}$ & $y=-271.91 x+103.3$ & 13.04 \\
NDI7 & 26 & $0.71^{* *}$ & $y=31.546 e^{2.2031 x}$ & 12.01 \\
STI & 26 & $0.75^{* *}$ & $y=23.524 x^{2.4856}$ & 9.02 \\
NDTI & 26 & $0.80^{* *}$ & $y=351.48 x^{1.0509}$ & 8.46 \\
\hline
\end{tabular}

Note: ${ }^{* *}$ demonstrated a significant at the $p<0.01$ probability level.

The CRIs were used in different linear and nonlinear regression models (Table 4) to estimate the WSC; therefore, the NDTI and STI were used in the power equation, and NDSAVI, NDI7, and NDI5 were correspondents to an exponential model. The SRNDI was used in a linear equation, whereas the maximum variation was obtained for NDTI, followed by STI (when compared to NDSAVI). The RMSD values were found to be in the range of $8.46 \%$ to $20.79 \%$. An assessment of the accuracy of each regression model equation for estimation exactness of the wheat straw cover is shown in Figure 6.

For the spatial distribution of WSC over the study region, we used the NDTI index to estimate the WSC, and a training model was then applied for the Landsat images. However, in our present study for mapping WSC, we divided the straw cover percentages into four categories/classes: (i) $0-40 \%$, (ii) $41 \%-60 \%$, (iii) $61 \%-80 \%$ and (iv) $81 \%-100 \%$, although the water body and urban areas are presented in Figure 7. The results indicated that the WSC ranged from $32 \%$ to $96 \%$, and the total rice-wheat rotation fields were $59.32 \%$, while urban and water occupying the area were $32.80 \%$ and $7.88 \%$, respectively (Table 5).

The estimate for WSC demonstrated that 10.84, 13.35, 18.57, and 16.56 per cent of the cultivated area was classified as $0-40 \%, 41-60 \%, 61-80 \%$ and $81-100 \%$, respectively. The highest WCS $(61-80 \%)$ were determined to be 18.57 per cent across the entire wheat-growing region. Therefore, these findings are consistent with those of our field measurements. Also, the overall accuracy of the estimated WSC classification was $84.61 \%$, and $k=0.76$, which satisfied the supervised classification method with a result that was better used for mapping crop straw cover on a large field scale. 

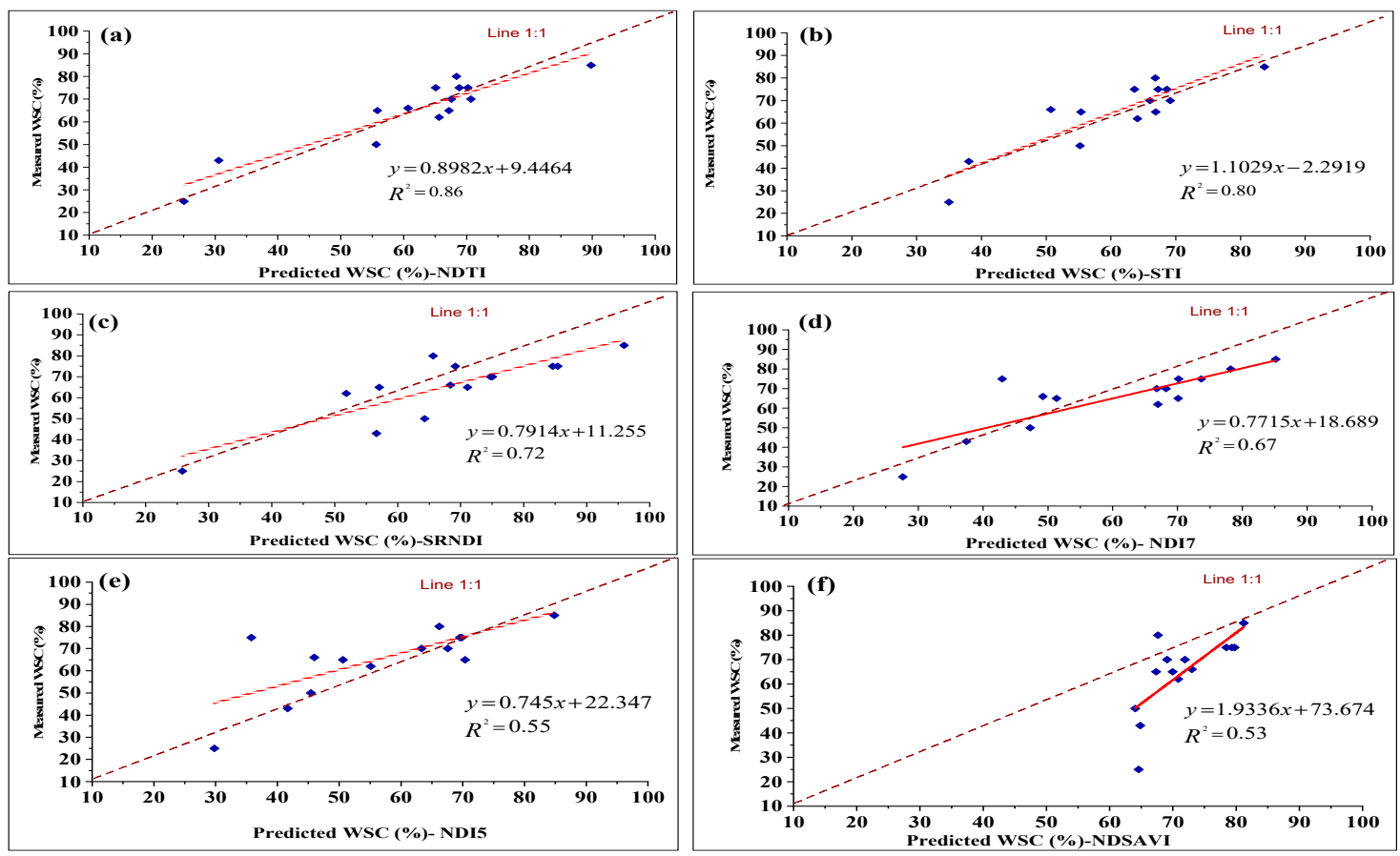

Figure 6. Relationship between the measured and predicated wheat straw cover (WCR, \%) for the testing dataset $(n=14)$. Note: (a) NDTI, (b) STI, (c) SRNDI, (d) NDI7, (e) NDI5, and (f) NDSAVI Spatial mapping of wheat straw cover (WSC).

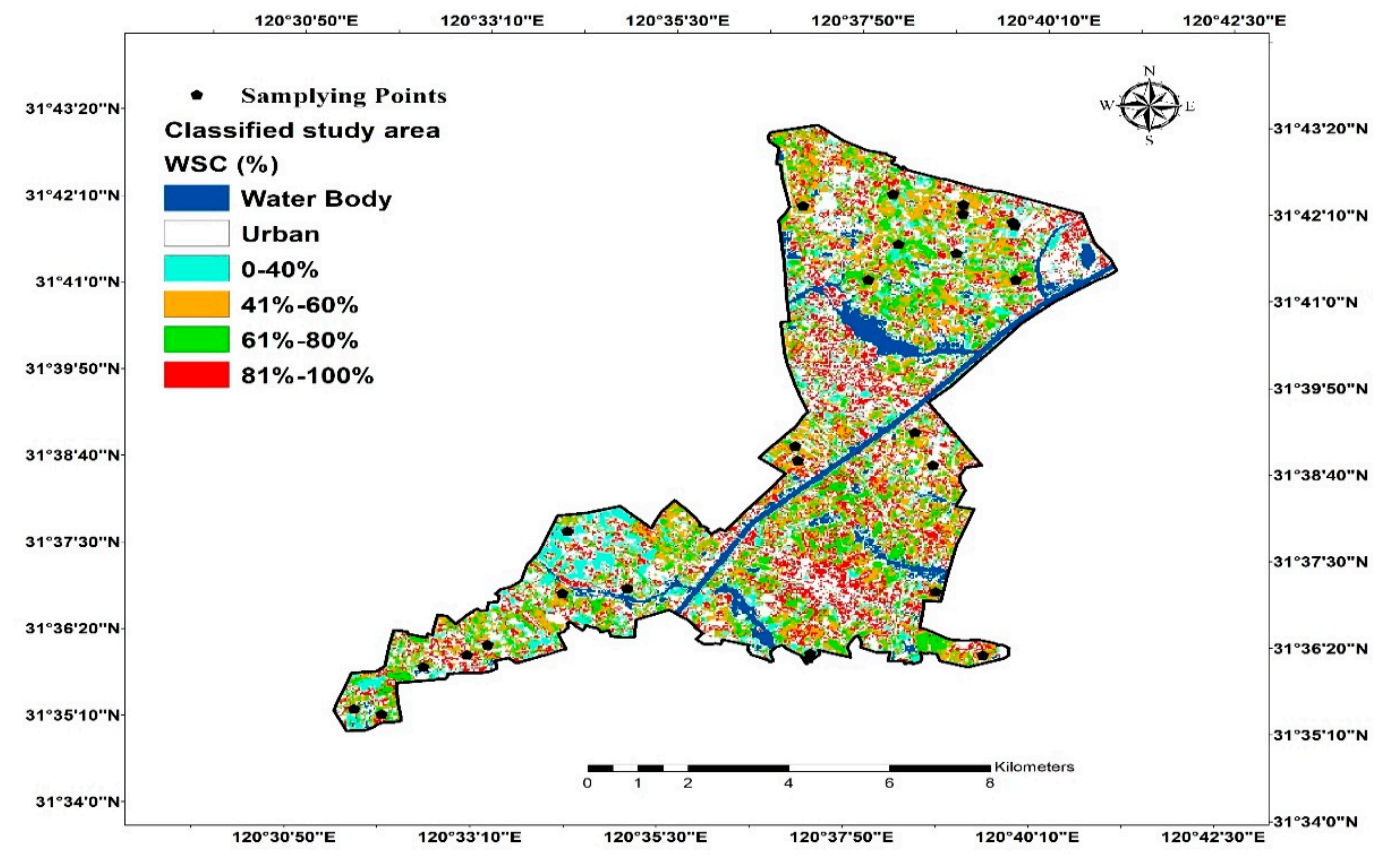

Figure 7. Distribution of land cover classification and WSC into four straw cover categories; (0-40\%, $41 \%-60 \%, 61 \%-80 \%$, and $81 \%-100 \%$ ) using CRIs values from Landsat OLI-TIRS images. 
Table 5. Different categories of WSC percentages under-sampling points $(n=40)$.

\begin{tabular}{|c|c|c|c|}
\hline Sr.No & Sample\# & Wheat Straw Cover Percentage & Category/Class \\
\hline 1 & CS-17 & 32 & \multirow{3}{*}{ Straw Cover: 0 to $40 \%$} \\
\hline 2 & CS-13 & 36 & \\
\hline 3 & CS-34 & 36 & \\
\hline 4 & CS-21 & 48 & \multirow{8}{*}{$\begin{array}{c}\text { Straw Cover: } 41 \% \text { to } \\
60 \%\end{array}$} \\
\hline 5 & CS-20 & 50 & \\
\hline 6 & CS-32 & 53 & \\
\hline 7 & CS-30 & 54 & \\
\hline 8 & CS-36 & 54 & \\
\hline 9 & CS-37 & 54 & \\
\hline 10 & CS-10 & 59 & \\
\hline 11 & CS-11 & 59 & \\
\hline 12 & CS-03 & 63 & \multirow{22}{*}{$\begin{array}{c}\text { Straw Cover: } 61 \% \text { to } \\
80 \%\end{array}$} \\
\hline 13 & CS-08 & 63 & \\
\hline 14 & CS-38 & 63 & \\
\hline 15 & CS-14 & 65 & \\
\hline 16 & CS-27 & 65 & \\
\hline 17 & CS-07 & 68 & \\
\hline 18 & CS-23 & 68 & \\
\hline 19 & CS-39 & 68 & \\
\hline 20 & CS-09 & 69 & \\
\hline 21 & CS-28 & 69 & \\
\hline 22 & CS-35 & 70 & \\
\hline 23 & CS-02 & 72 & \\
\hline 24 & CS-04 & 72 & \\
\hline 25 & CS-18 & 72 & \\
\hline 26 & CS-25 & 72 & \\
\hline 27 & CS-26 & 72 & \\
\hline 28 & CS-31 & 72 & \\
\hline 29 & CS-19 & 77 & \\
\hline 30 & CS-01 & 77 & \\
\hline 31 & CS-05 & 77 & \\
\hline 32 & CS-12 & 77 & \\
\hline 33 & CS-33 & 77 & \\
\hline 34 & CS-22 & 81 & \multirow{7}{*}{$\begin{array}{c}\text { Straw Cover: } 81 \% \text { to } \\
100 \%\end{array}$} \\
\hline 35 & CS-24 & 81 & \\
\hline 36 & CS-40 & 81 & \\
\hline 37 & CS-06 & 84 & \\
\hline 38 & CS-29 & 86 & \\
\hline 39 & CS-16 & 90 & \\
\hline 40 & CS-15 & 96 & \\
\hline
\end{tabular}

3.3. Rice Yield Performance with Different WSC Percentages

\subsubsection{Algorithms to Classify Rice Fields}

The mapping result of paddy rice fields in the study region was derived from Landsat 7 (ETM+) and Landsat 8 (OLI-TIRS) data (Figure 8). The paddy fields were found to be distributed over the study area, with a total area of approximately 10,607 acres. Furthermore, the spatial pattern of rice from the Landsat satellite is generally similar to the observed GPS ground truth survey data and local government data, with an overall accuracy of $90 \%(\kappa=0.81)$, which is thought to be in accordance with the satellite data. Through a supervised classification method, it was detected that the paddy field areas (Figure 8 ) should be classified as Early Rice Planting (36.48\%), followed by Late Rice Planting (22.89\%) over the study region based on NDVI data from 14 July 2017 (DOY 194). 


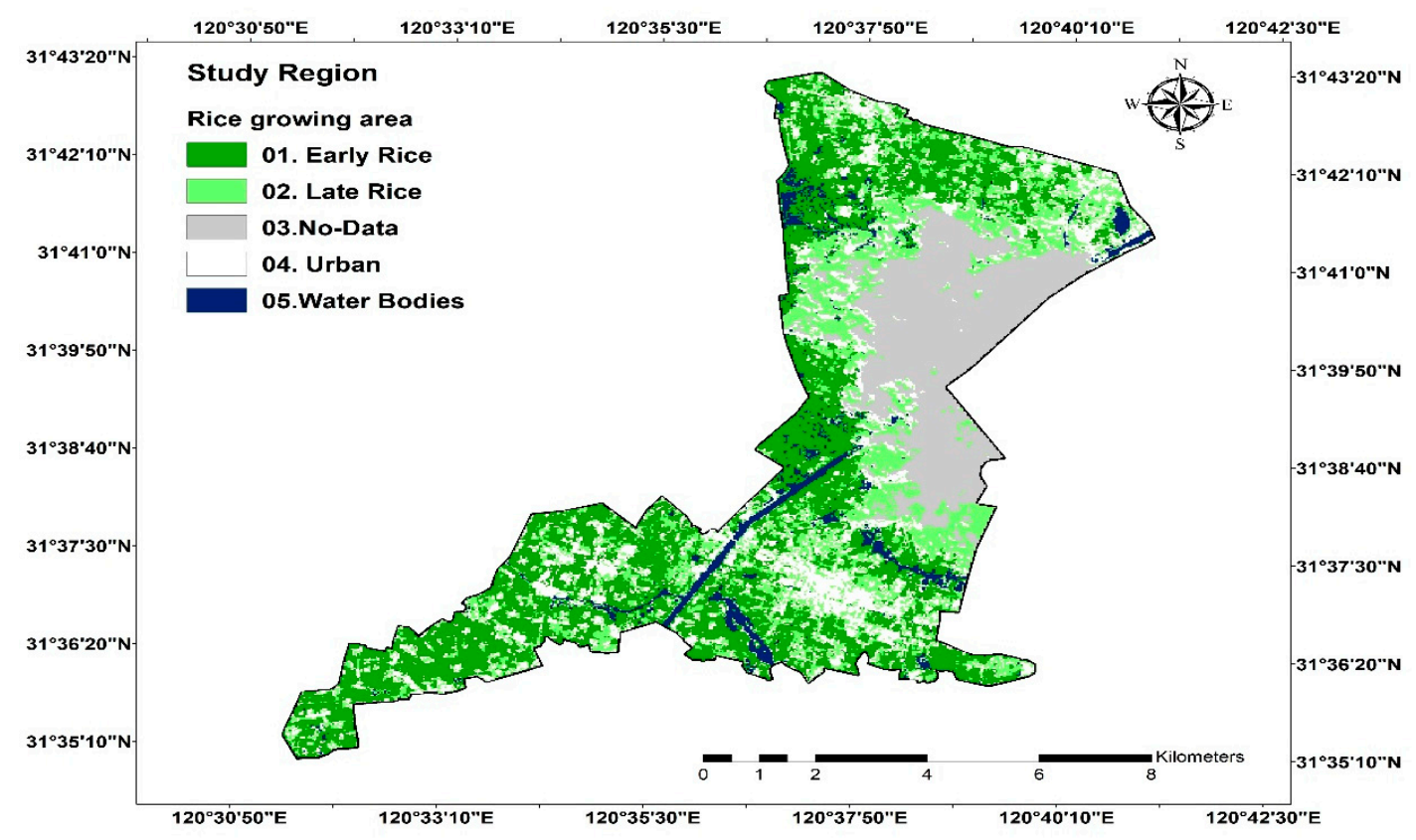

Figure 8. Classified distribution of paddy areas by various planting times.

\subsubsection{Evolution of NDVI with Different Straw Covers}

The constructed NDVI temporal profiles throughout the rice season of 2017 were much clearer during the cropping stages (e.g., transplantation, tillering, heading/booting, and flowering) with the different straw cover percentages in the rice field (Figure 9). The NDVI values of different rice crop vegetation phases demonstrate that higher NDVI was determined during the peak maximum greenness stages in August and September 2017, and the mean NDVI value was found to be 0.916, whereas the NDVI values had considerably fallen from DOY: 282 to DOY: 314 due the ripening stage (e.g., milk and dough phase). Moreover, the lower NDVI (0.359) was observed in November 2017 at the maturity stage of the rice crop.

Furthermore, the relationship between the maximum NDVI and the different WSC percentages for the respective sampling points $(n=40)$ of the study area are presented in Figure 10, while the NDVI values were considerable at the peak stage (DOY: 234-258) during the rice cycle for all corresponding field plots. The summarized results show that a positive correlation exists and fits to a moderate linear regression model with $R^{2}=0.67$, whereas the highest and lowest normalized difference vegetation index values were found with WSC-68\% (NDVI $=0.86)$ and WSC-33\% (NDVI $=0.60)$, respectively.

\subsubsection{Establishment and Performance of the Rice Yield Model}

In this study, a regression-based crop yield model was developed (Equation (2)) on the training dataset $(n=26)$ between the peak NDVI and average crop yield of sampling points for the rice season of 2017 (Figure S4). Furthermore, for the performance of rice yield model, the recorded grain yield data were obtained from the ground truth survey data and statistical yearbooks of Changshu district Suzhou, 2017 [49]. The model was fitted to an exponential equation, and the R-squared $\left(R^{2}\right)$ and RSMD were determined to be $0.85 \%$ and $16.53 \%$, respectively. Figure 11 shows that the relationship between the measured and predicted rice crop yield was significantly $(p<0.01)$ correlated with $R^{2}=0.90$ and $\mathrm{RSMD}=6.24 \%$ over the study region. 


$$
y=5501 e^{0.5006 \times N D V I}
$$

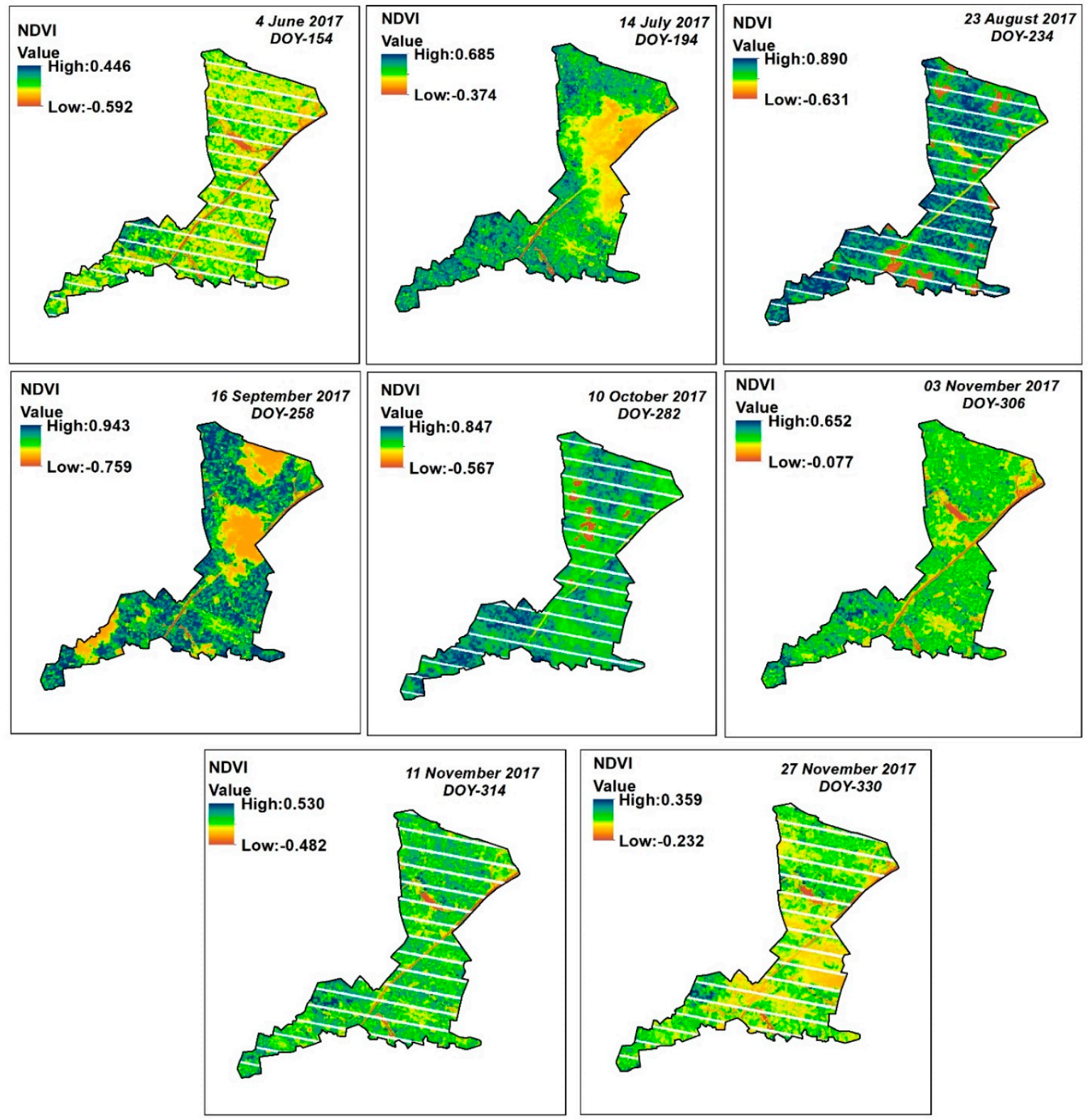

Figure 9. Showing spatial distribution of normalized difference vegetation index (NDVI) at different stages of paddy fields during the rice season of 2017. 


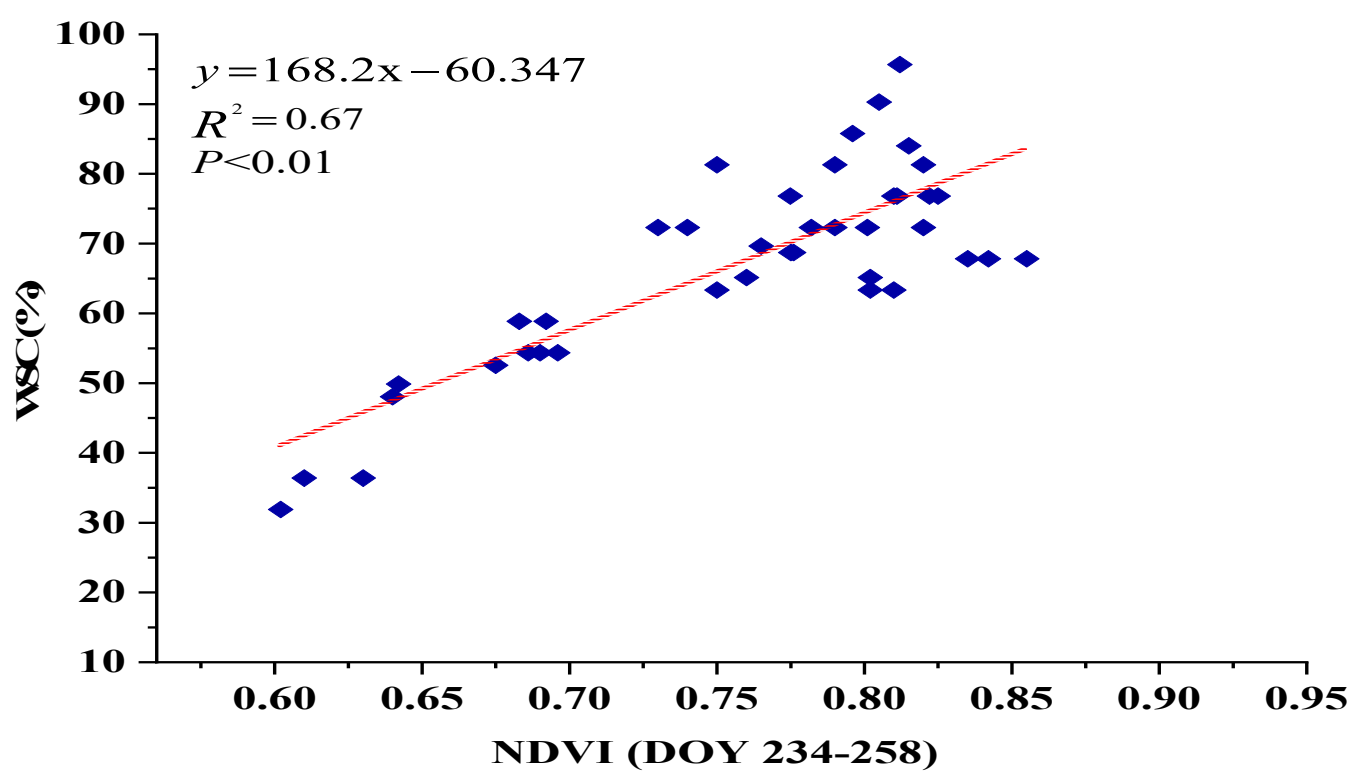

Figure 10. Relationship between NDVI and WSC with different percentages for corresponding sampling points.

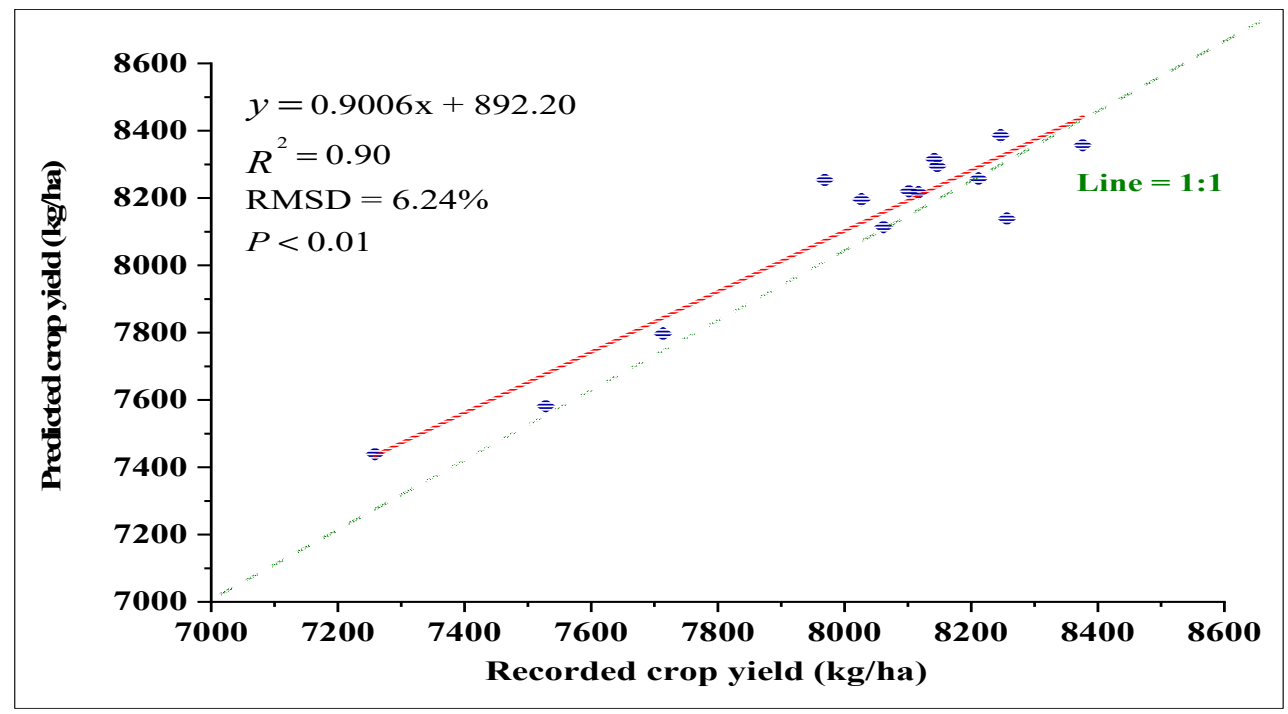

Figure 11. Correlation between the recorded and predicted rice crop yields for model validation through the testing dataset $(n=14)$ over the study area.

\subsubsection{Estimation of Rice Yield with Different Straw Cover Percentages}

For the determination of rice grain yield with different wheat straw percentages, we applied Equation (2) to all the sampling points $(n=40)$ through NDVI values over the study area (Table S2). These finding showed that the highest yield was recorded in CS-39, with $68 \%$ WCS $(8439.67 \mathrm{~kg} / \mathrm{ha})$, whereas the bivariate kernel density estimates (Figure 12) presented a higher yield density $(0.082)$, which was observed in the range WSC $65-78 \%$, with an average yield from 8.3 to 8.4 ton/ha compared to that of other straw cover percentage plots. 
(a)
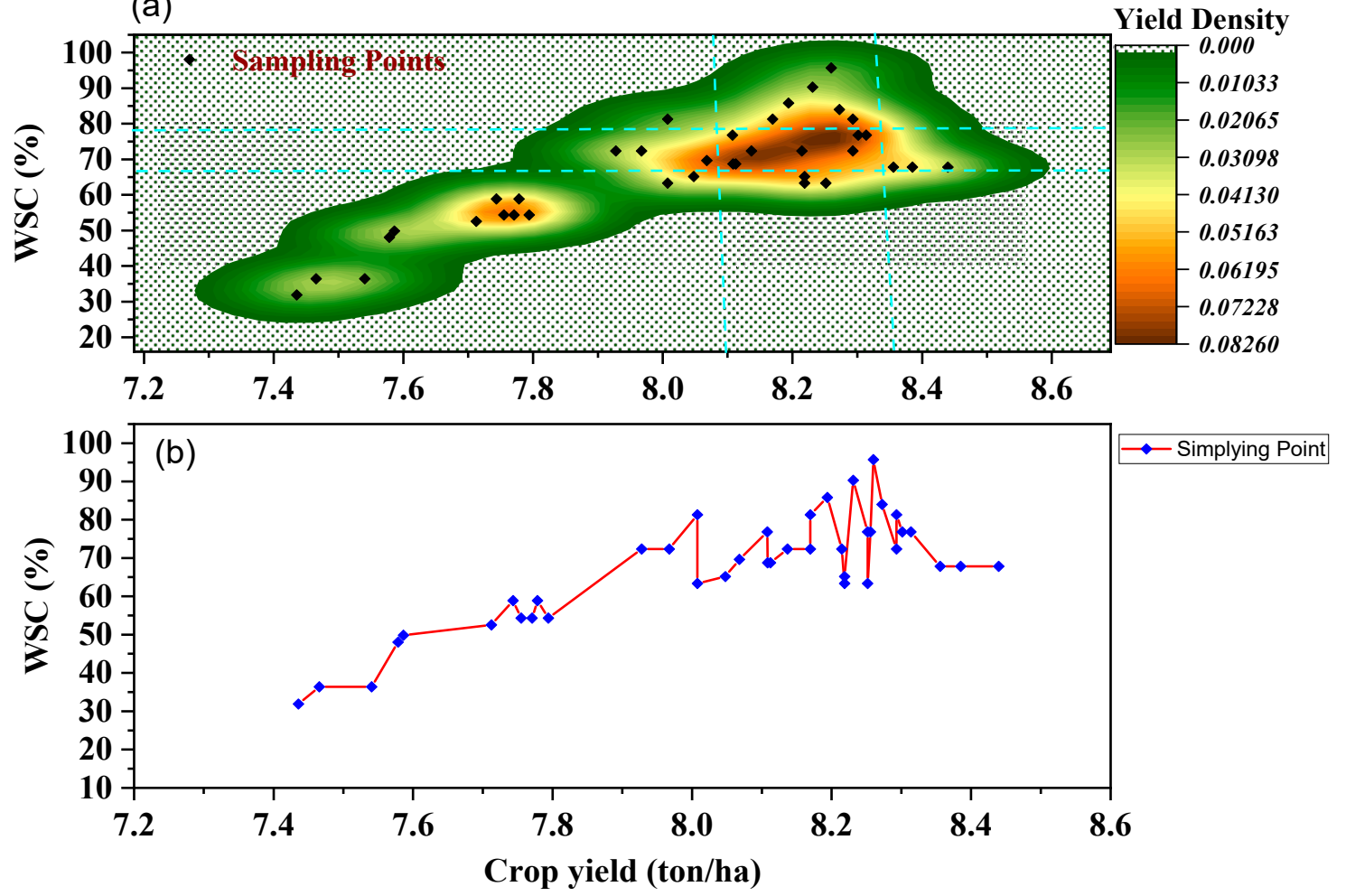

Figure 12. Showing the kernel density plot between WSC and rice crop yield for sampling points $(n=40)$ over the study area. Note: WSC: Wheat straw cover, (a) kernel density plot and (b) line plot between wheat straw cover (\%) and crop yield (ton/ha).

\section{Dicussion}

Accurate information on CSC can support several benefits, including large-scale assessments, and affects the amount of straw utilized under a tillage method on cropping systems and water resources with productivity analyses. Therefore, the precise measurements and robust methods used to assess the wheat straw cover percentage and its performance on crop production in a large region is still evolving. Currently, only limited applications/methods are available to estimate and map WSC on a regional scale. Thereby, in this study, we aim to fill these gaps through the currently available RS-based indices and Landsat products, both of which are openly accessible with high-resolution spatial data and are suitable for the RS community to minimize the quantity of data and the processing time necessary for the analysis.

However, in our approach, the training dataset was used for developing regression models, and the equation was applied to the testing dataset to predict the straw cover percentage and crop yield. The highest and lowest straw cover percentages were determined to be $96 \%$ and $25 \%$, respectively, which could be due to the accumulation of plenty of wheat residues at the sampling locations. The cover percentage was dependent on how much density existed with the straw on the ground, and these findings were consistent with those of Asadi et al. [50] and Pforte et al. [51].

Moreover, the performance of NDTI and STI (Figure 6) indices was much better than the other indices in forecasting WSC. Similar results were stated by Sharma et al. [52], who stated that there was a strong correlation between the straw cover and RS-based NDTI and STI, with $R^{2}$ values of 0.89 and 0.78 , respectively, for the testing dataset $(n=30)$ for 2014, in central Nebraska. However, Thoma et al. [22] indicated that the CRIs Multiband (CRIM) performed better on corn and bean residue because crop residues have different colors and textures, and absorb water differently [53,54]. In this study, the NDTI and STI were measured from band- 6 and band- 7 of the Landsat- 8 OLI, and band- 5 and band- 7 for Landsat-ETM+ image data and results showed a positive correlation to the WSC estimation (Table 5). 
These findings are also in agreement with Jin et al. [26] and Zheng et al. [32], who demonstrated that the NDTI and STI indices were more suitable for estimating the crop straw cover percentage with multitemporal Landsat ETM+ and OLI-TIRS images on a regional scale.

To map the spatial distribution of the WSC over the study region (Figure 7) was distributed into four categories, and the classification results revealed that total RWC fields were $59.32 \%$. These findings are consistent with our field measurements, and the results were better used for mapping crop straw cover at a large field scale. Similar results to CRC mapping under different crops were observed by Jin et al. [26] and Sharma et al. [52], who concluded that the combination of multispectral Landsat images with tillage indices was feasible to estimate and map the CRC over a regional scale. The researchers also reported that the accurate mapping of CRC into different percentage categories has many advantages, including large-scale evaluations of varying tillage practices on soil quality, SOC storage, water resources, cropping phenology analyses, policy decisions, soil carbon, and cropping simulation models for agricultural sustainability.

Consequently, the rice fields were at the tillering stage at the time of acquiring the Landsat image for classification. Hence, the spatial distribution for the rice sowing pattern confirmed that the Landsat ancillary data and the NDVI can be suitable for mapping the rice cropland classes at a regional scale. The method assessment results are in agreement with Gumma et al. [55], who reported that rice classes were appropriately identified by satellite imagery using field data, temporal NDVI signatures, and GPS referenced digital images for each rice class. In addition, Sun et al. [56], upgraded the data reconstruction and rice growth calendar regionalization to map single, early, and late rice paddies from 2001 to 2006 in China. Moreover, Liu et al. [57] and Zhang et al. [58] suggested that the Landsat-based product would well demonstrate the two cropland classes (paddy and non-flooded), which were aggregated to total cropland.

Moreover, the NDVI observations (Figure 9) for the 2017 rice season showed low NDVI at the early stage, and gradually increased at the tillering stage, and then again decreased at the mature stage of rice crop. These observations are in agreement with earlier studies by Minh and Chien [59], Peng et al. [60], and Xiao et al. [38]. These researchers investigated the changes in NDVI values at different rice stages. The results were higher at $0.8-1.0$, which corresponds to the maximum growing stage (peak season), and then decreased to approximately 0-0.4 when the season ended.

Furthermore, the estimation accuracy of the crop yield regression model between the recorded and predicted rice yield values over the study site was validated in regards to results (Figure 11). These findings are strongly supported by Siyal et al. [61], who reported that Landsat imagery with the NDVI vegetation index was a better analysis method for estimating the rice crop yield over a large scale. Besides, a positive relationship was observed with $R^{2}=0.94$ between the reported rice crop yield and the NDVI at the peak of the growing season for the years 2006 to 2013. Similarly, another research study demonstrated that the NDVI values at 63 days after the planting and ground-based yield observation had strong exponential relations $\left(R^{2}=0.85\right)$ during the model development phase, whereas the application phase of the model revealed a highly strong relationship, with $R^{2}=0.93$ between ground-based estimates and the forecasted rice yield over the study area, by Nuarsa et al. [62].

Previous studies by Zhang et al. [63] showed that straw cover application is a key management strategy to enhance crop production. However, the result obtained in this study with regards to rice yield under a different WSC percentage (Figure 12) demonstrated that the highest yield was recorded under the field with straw cover range from $65 \%$ to $78 \%$, as compared to other sampling points. These observations are strongly supported by Memon et al. [35], who studied wheat straw applications with $60 \%$ of the amount improved for the soil fertility and to increase the rice grain yield by 7.95-8.63 ton/ha under a rice-wheat rotation system in China. Also, Hejazi et al. [64] and Song et al. [65], reported that the application of wheat straw incorporation enhanced the emergence rate, growth quality at the seedling stage, and the grain yield of the rice crop.

Therefore, the predicted yield data indicated the accuracy and reliability of the outcomes obtained and the conclusion drawn. Moreover, by applying this approach, it can be conceivable to estimate 
the rice yield with a different wheat straw cover percentage in the rice-wheat cropping system over a large-scale agricultural region.

\section{Conclusions}

In this study, we used multitemporal Landsat-7 (ETM+) and Landsat-8 (OLI/TIRS) satellite data by using remote-sensing-based (CRIs) and VIs to develop a regression model for an assessment of WSC and the performance of rice crop over the study area in Changshu County, China. The resulting data indicated that NDTI, STI, NDI7, and SRNDI were strongly correlated with WSC percentages. In particular, NDTI performed best at mapping the WSC percentage in different categories with an overall accuracy of $84.61 \%(\kappa=0.76)$ compared to other CRI indices. The NDTI also showed the highest $R^{2}=0.86$ between the linear relationship for the predicated and measured wheat straw covers. Moreover, the classification of the resultant paddy rice map had an overall accuracy of $90 \%$ based on the validation of data derived from the ground truth observation, along with agricultural census data published by the statistical book of Suzhou-2017 at the provincial level for the sampling points. The rice yield model was developed by correlating the sampling points peak NDVI values and rice production obtained through ground recorded data with $R$-squared $\left(R^{2}=0.85\right)$. In addition, the findings also demonstrated that the highest estimated yield was recorded with $68 \%$ WCS $(8439.67 \mathrm{~kg} / \mathrm{ha})$, and the bivariate kernel density estimates revealed that the maximum yield density $(0.082)$ was observed in the range of a $65-78 \%$ straw cover percentage, with an average yield of 8300 to $8400 \mathrm{~kg} / \mathrm{ha}$. Therefore, together with our efforts, it can be strongly suggested that the Landsat (ETM+ and OLI-TIRS) imagery with higher temporal resolution and RS based indices are capable of monitoring and estimating the WSC percentages, which evaluate the influence of different WSC percentages on rice grain production over a large area. Similarly, the use of the RS approach of the present study will serve as a basis for assessment of agriculture risk management as well as improving data visualization and the decision-making process with the support of satellite maps data in regards to monitoring agriculture crops., This information can be used as an incredible tool in collaboration between stakeholders of farm risk management, insurance providers companies, and governmental agencies to providing suitable financial hedging instruments for farmers [66,67]. Furthermore, this study will enable us to conduct future research on different satellite images with higher temporal resolutions such as sentinel-2, Gaofen-1, and Gaofen-2, under the distinct climate zones, cropping pattern, and farming practices in the agricultural cultivation area for determining the impacts of the straw cover percentages on the crop yield and soil quality in agroecosystem by using RS/GIS techniques. This information will help policymakers and stakeholders to understand the responses and adaptations of agricultural systems in different regions to address concerns regarding global climate change and offers the perspective of a truly transformative environment for the agricultural intensification required to meet food security and enhanced livelihood targets for long-term sustainability.

Supplementary Materials: The following are available as supplementary data/ online at http://www.mdpi.com/ 2071-1050/11/19/5369/s1, Table S1: Detail of wavelength of spectral bands with a spatial resolution of Landsat 7 and Landsat 8 satellites, Table S2: Crop yields under different percentage of WSC for sampling point during rice season of 2017. Figure S1: Performa templates for ground trothing survey, Figure S2: Measurement of crop straw cover and sampling design at sampling sites, Figure S3. Methodology workflow. The ArcMap model-builder illustrates the 4 main processing phases: (i) Import of full Landsat scene, (ii) Extraction of Band for Study area (iii) Indices Analysis and (iv) Extraction of results in excel spreadsheet for further analysis, Figure S4: Relationship between NDVI under different percentage of wheat straw cover and rice crop yield for sampling point of study region.

Author Contributions: Conceptualization, M.S.M.; Data curation, M.S.M. and Q.H.; Formal analysis, C.S., Q.H. and H.Y.; Funding acquisition, Z.J. and C.J.; Investigation, W.X.; Methodology, M.S.M.; Project administration, Z.J. and J.C.; Resources, C.J.; Software, M.S.M., Z.J. and W.X.; Supervision, C.J.; Validation, M.S.M.; Visualization, C.J.; Writing-original draft, M.S.M. and C.J.; Writing-review \& editing, M.S.M. and C.J.

Funding: This study was sponsored by the National Natural Science Foundation of China under Grant \# 51275250. 
Acknowledgments: We would like to thank farmers who cooperate in field survey and supplied us the productive data of wheat and rice crop. The first author is extremely thankful to Chinese Scholarship Council (CSC) for providing scholarship to pursue Ph.D. degree. Finally, we would like to thank the reviewers for recommendations which improved the manuscript.

Conflicts of Interest: The authors declare no conflict of interest.

\section{References}

1. Anikwe, M.A.N.; Ubochi, J.N. Short-term changes in soil properties under tillage systems and their effect on sweet potato (Ipomea batatas L.) growth and yield in an Ultisol in south-eastern Nigeria. Aust. J. Soil Res. 2007, 45, 351-358. [CrossRef]

2. Paustian, K.; Lehmann, J.; Ogle, S.; Reay, D.; Robertson, G.P.; Smith, P. Climate-smart soils. Nature 2016, 532, 49-57. [CrossRef]

3. Wilhelm, W.W.; Johnson, J.M.F.; Hatfield, J.L.; Voorhees, W.B.; Linden, D.R. Crop and Soil Productivity Response to Corn Residue Removal: A Literature Review. Agron. J. 2004, 96, 1-17. [CrossRef]

4. Zougmoré, R.; Jalloh, A.; Tioro, A. Climate-smart soil water and nutrient management options in semiarid West Africa: A review of evidence and analysis of stone bunds and zaï techniques. Agric. Food Secur. 2014, 3. [CrossRef]

5. Bannari, A.; Pacheco, A.; Staenz, K.; McNairn, H.; Omari, K. Estimating and mapping crop residues cover on agricultural lands using hyperspectral and IKONOS data. Remote Sens. Environ. 2006, 104, 447-459. [CrossRef]

6. Blanco-Canqui, H.; Lal, R. Corn Stover Removal for Expanded Uses Reduces Soil Fertility and Structural Stability. Soil Sci. Soc. Am. J. 2009, 73, 418. [CrossRef]

7. Power, J.F.; Koerner, P.T.; Doran, J.W.; Wilhelm, W.W. Residual Effects of Crop Residues on Grain Production and Selected Soil Properties. Soil Sci. Soc. Am. J. 1998, 1397, 1393-1397. [CrossRef]

8. Lal, R. Soil carbon sequestration to mitigate climate change. Geoderma 2004, 123, 1-22. [CrossRef]

9. Ussiri, D.A.N.; Lal, R. Long-term tillage effects on soil carbon storage and carbon dioxide emissions in continuous corn cropping system from an alfisol in Ohio. Soil Tillage Res. 2009, 104, 39-47. [CrossRef]

10. CTIC. National Survey of Conservation Tillage Practices; CTIC: West Lafayette, IN, USA, 2010.

11. Baumhardt, R.L.; Stewart, B.A.; Sainju, U.M. North American soil degradation: Processes, practices, and mitigating strategies. Sustainability 2015, 7, 2936-2960. [CrossRef]

12. Wischmeier, W.H.; Smith, D.D. Predicting Rainfall Erosion Losses: A Guide to Conservation Planning; U.S. Department Agriculture Handbook No. 537; U.S. Department Agriculture: Washington, DC, USA, 1978; pp. 1-69. [CrossRef]

13. Abrahamson, D.A.; Causarano, H.J.; Williams, J.R.; Norfleet, M.L.; Franzluebbers, A.J. Predicting soil organic carbon sequestration in the southeastern United States with EPIC and the soil conditioning index. J. Soil Water Conserv. 2009, 64, 134-144. [CrossRef]

14. Brown, D.J.; Hunt, E.R.; Izaurralde, R.C.; Paustian, K.H.; Rice, C.W.; Schumaker, B.L.; West, T.O. Soil organic carbon change monitored over large areas. EOS (Washington DC) 2010, 91, 441-442. [CrossRef]

15. Rodriguez, H.G.; Popp, J.; Maringanti, C.; Chaubey, I. Selection and placement of best management practices used to reduce water quality degradation in Lincoln Lake watershed. Water Resour. Res. 2011, 47. [CrossRef]

16. Mcnairn, H.; Protz, R. Mapping corn residue cover on agricultural fields in oxford county, ontario, using thematic mapper. Can. J. Remote Sens. 1993, 19, 152-159. [CrossRef]

17. Hartwig, R.O.; Laflen, J.M. A meterstick method for measuring crop residue cover [in preventing soil erosion]. Bibliogr. Inf. 1978, 33, 33.

18. Laflen, J.M.; Amemiya, M.; Hintz, E.A. Measuring crop residue cover. J. Soil Water Conserv. 1981, 36, $341-343$.

19. Morrison, J.E., Jr.; Huang, C.H.; Lightle, D.T.; Daughty, C.S.T. Residue measurement techniques. J. Soil Water Conserv. 1993, 48, 478-483.

20. Kline, R. Estimating Crop Residue Cover for Soil Erosion Control; Ministry of Agriculture: Abbotsford, BC, Canada, 2000.

21. Daughtry, C.S.T.; Serbin, G.; Reeves, J.B.; Doraiswamy, P.C.; Hunt, E.R. Spectral reflectance of wheat residue during decomposition and remotely sensed estimates of residue cover. Remote Sens. 2010, 2, $416-431$. [CrossRef] 
22. Thoma, D.P.; Gupta, S.C.; Bauer, M.E. Evaluation of optical remote sensing models for crop residue cover assessment. J. Soil Water Conserv. 2004, 59, 224-233.

23. Daughtry, C.S.T.; McMurtrey, J.E.; Chappelle, E.W.; Hunter, W.J.; Steiner, J.L. Measuring crop residue cover using remote sensing techniques. Theor. Appl. Climatol. 1996, 54, 17-26. [CrossRef]

24. Nagler, P.L.; Daughtry, C.S.T.; Goward, S.N. Plant litter and soil reflectance. Remote Sens. Environ. 2000, 71, 207-215. [CrossRef]

25. Daughtry, C.S.T. Discriminating crop residues from soil by shortwave infrared reflectance. Agron. J. 2001, 93, 125-131. [CrossRef]

26. Jin, X.; Ma, J.; Wen, Z.; Song, K. Estimation of maize residue cover using Landsat-8 OLI image spectral information and textural features. Remote Sens. 2015, 7, 14559-14575. [CrossRef]

27. Serbin, G.; Daughtry, C.S.T.; Hunt, E.R.; Brown, D.J.; McCarty, G.W. Effect of Soil Spectral Properties on Remote Sensing of Crop Residue Cover. Soil Sci. Soc. Am. J. 2009, 73, 1545. [CrossRef]

28. Qi, J.; Marsett, R.; Heilman, P.; Biedenbender, S.; Moran, S.; Goodrich, D.; Weltz, M. RANGES improves satellite-based information and land cover assessments in Southwest United States. EOS (Washington DC) 2002, 83. [CrossRef]

29. Chevrier, M.; Bannari, A.; Deguise, J.C.; McNairn, H.; Staenz, K. Hyperspectal narrow-wavebands for discriminating crop residue from bare soil. In Proceedings of the 2002 IEEE International Geoscience and Remote Sensing Symposium, IGARSS '02, Toronto, ON, Canada, 24-28 June 2002; Volume 4, pp. 2202-2204.

30. Bannari, A.; Haboudane, D.; Bonn, F. Intérêt du moyen infrarouge pour la cartographie des résidus de cultures. Can. J. Remote Sens. 2000, 26, 384-393. [CrossRef]

31. van Deventer, A.P.; Ward, A.D.; Gowda, P.H.; Lyon, J.G. Using thematic mapper data to identify contrasting soil plains and tillage practices. Photogramm. Eng. Remote Sens. 1997, 63, 87-93.

32. Zheng, B.; Campbell, J.B.; de Beurs, K.M. Remote sensing of crop residue cover using multi-temporal Landsat imagery. Remote Sens. Environ. 2012, 117, 177-183. [CrossRef]

33. Frolking, S.; Qiu, J.; Boles, S.; Xiao, X.; Liu, J.; Zhuang, Y.; Li, C.; Qin, X. Combining remote sensing and ground census data to develop new maps of the distribution of rice agriculture in China. Glob. Biogeochem. Cycles 2002, 16, 10-38. [CrossRef]

34. Kumari, M.; Chakraborty, D.; Gathala, M.K.; Pathak, H.; Dwivedi, B.S.; Tomar, R.K.; Garg, R.N.; Singh, R.; Ladha, J.K. Soil Aggregation and Associated Organic Carbon Fractions as Affected by Tillage in a Rice-Wheat Rotation in North India. Soil Sci. Soc. Am. J. 2011, 75, 560-567. [CrossRef]

35. Memon, M.S.; Guo, J.; Tagar, A.A.; Perveen, N.; Ji, C.; Memon, S.A.; Memon, N. The effects of tillage and straw incorporation on soil organic carbon status, rice crop productivity, and sustainability in the rice-wheat cropping system of Eastern China. Sustainability 2018, 10, 961. [CrossRef]

36. Okamoto, K. Estimation of rice-planted area in the tropical zone using a combination of optical and microwave satellite sensor data. Int. J. Remote Sens. 1999, 20, 1045-1048. [CrossRef]

37. Van Niel, T.G.; McVicar, T.R.; Fang, H.; Liang, S. Calculating environmental moisture for per-field discrimination of rice crops. Int. J. Remote Sens. 2003, 24, 885-890. [CrossRef]

38. Xiao, X.; Boles, S.; Liu, J.; Zhuang, D.; Frolking, S.; Li, C.; Salas, W.; Moore, B. Mapping paddy rice agriculture in southern China using multi-temporal MODIS images. Remote Sens. Environ. 2005, 95, 480-492. [CrossRef]

39. Bachelet, D. Rice paddy inventory in a few provinces of China using AVHRR data. Geocarto Int. 1994, 10, 23-38. [CrossRef]

40. Poh, T.C.; Yi, K.J.; Sing, L.K.; Bahari, S.; Tat, E.H.; Teik, C.H. Applications of remote sensing in the monitoring of rice crops. J. Inst. Eng. Malays. 2006, 67, 2-11.

41. Miglietta, P.P.; Micale, R.; Sciortino, R.; Caruso, T.; Giallanza, A.; La Scalia, G. The sustainability of olive orchard planting management for different harvesting techniques: An integrated methodology. J. Clean. Prod. 2019, 238, 117989. [CrossRef]

42. Aksoy, S.; Yalniz, I.Z.; Taşdemir, K. Automatic detection and segmentation of orchards using very high resolution imagery. IEEE Trans. Geosci. Remote Sens. 2012, 50, 3117-3131. [CrossRef]

43. Goward, S.N.; Markham, B.; Dye, D.G.; Dulaney, W.; Yang, J. Normalized difference vegetation index measurements from the advanced very high resolution radiometer. Remote Sens. Environ. 1991, 35, 257-277. [CrossRef] 
44. Friedl, M.A.; McIver, D.K.; Hodges, J.C.F.; Zhang, X.Y.; Muchoney, D.; Strahler, A.H.; Woodcock, C.E.; Gopal, S.; Schneider, A.; Cooper, A.; et al. Global land cover mapping from MODIS: Algorithms and early results. Remote Sens. Environ. 2002, 83, 287-302. [CrossRef]

45. USGS. U.S. Geological Survey Landsat 8: U.S. Available online: https://pubs.usgs.gov/fs/2013/3060/ (accessed on 12 November 2018).

46. Roy, D.P.; Kovalskyy, V.; Zhang, H.K.; Vermote, E.F.; Yan, L.; Kumar, S.S.; Egorov, A. Characterization of Landsat-7 to Landsat- 8 reflective wavelength and normalized difference vegetation index continuity. Remote Sens. Environ. 2016, 185, 57-70. [CrossRef]

47. Rouse, J.W., Jr.; Haas, R.; Schell, J.; Deering, D. Monitoring Vegetation Systems in the Great Plains with ERTS; Technical Presentations, NASA SP-351; NASA: Washington, DC, USA, 1974; p. 309.

48. IBM Corp. IBM SPSS Statistics for Windows; Version 23.0; IBM Corp: Armonk, NY, USA, 2015.

49. Changshu-Statistics. Suzhou Statistical Year Book; China Statistics Press: Beijing, China, 2017; Chapter 3.

50. Asadi, V.; Jafari, A.; Moradi, M.; Rasekhi, R. Precise measurement of residue cover by means of image processing techniques. In Proceedings of the International Conference on Agricultural Engineering AGENG 2010, Clermont-Ferrand, France, 6-8 September 2010; p. 391.

51. Pforte, F.; Wilhelm, B.; Hensel, O. Evaluation of an online approach for determination of percentage residue cover. Biosyst. Eng. 2012, 112, 121-129. [CrossRef]

52. Sharma, V.; Irmak, S.; Kilic, A.; Sharma, V.; Gilley, J.E.; Meyer, G.E.; Knezevic, S.Z.; Marx, D. Quantification and Mapping of Surface Residue Cover for Maize and Soybean Fields in South Central Nebraska. Trans. ASABE 2016, 59, 925-939. [CrossRef]

53. Arsenault, É.; Bonn, F. Evaluation of soil erosion protective cover by crop residues using vegetation indices and spectral mixture analysis of multispectral and hyperspectral data. CATENA 2005, 62, 157-172. [CrossRef]

54. Pacheco, A.; McNairn, H. Evaluating multispectral remote sensing and spectral unmixing analysis for crop residue mapping. Remote Sens. Environ. 2010, 114, 2219-2228. [CrossRef]

55. Gumma, M.K.; Mohanty, S.; Nelson, A.; Arnel, R.; Mohammed, I.A.; Das, S.R. Remote sensing based change analysis of rice environments in Odisha, India. J. Environ. Manag. 2015, 148, 31-41. [CrossRef] [PubMed]

56. Sun, H.; Huang, J.; Huete, A.R.; Peng, D.; Zhang, F. Mapping paddy rice with multi-date moderate-resolution imaging spectroradiometer (MODIS) data in China. J. Zhejiang Univ. Sci. A 2009, 10, 1509-1522. [CrossRef]

57. Liu, M.; Tang, X.; Liu, J.; Zhuang, D. Research on scaling effect based on $1 \mathrm{~km}$ grid cell data. J. Remote Sens. 2001, 5, 183-190. (In Chinese)

58. Bi, Y.Y.; Zheng, Z.Y. Actual changes of cultivated area since the founding of the new China. Resour. Sci. 2000, 22, 8-12. (In Chinese)

59. Minh, V.Q.; Chien, H.V. Monitoring and delineating the progress of rice sowing and cropping calendar assisting in early warning pest and desease in Mekong Delta, Vietnam. In Proceedings of the 34th Asian Conference on Remote Sensing (ACRS 2013), Bali, Indonesia, 20-24 October 2013.

60. Peng, D.; Huete, A.R.; Huang, J.; Wang, F.; Sun, H. Detection and estimation of mixed paddy rice cropping patterns with MODIS data. Int. J. Appl. Earth Obs. Geoinf. 2011, 13, 13-23. [CrossRef]

61. Siyal, A.A.; Siyal, A.G.; Mahar, R. Remote sensing and GIS based wheat crop acreage and yield estimation of district Hyderabad, Pakistan. Mehran Univ. Res. J. Eng. Technol. 2015, 34, 33-39.

62. Nuarsa, I.W.; Nishio, F.; Hongo, C. Rice Yield Estimation Using Landsat ETM+ Data and Field Observation. J. Agric. Sci. 2012, 3, 45-56. [CrossRef]

63. Zhang, P.; Wei, T.; Jia, Z.; Han, Q.; Ren, X.; Li, Y. Effects of straw incorporation on soil organic matter and soil water-stable aggregates content in semiarid regions of Northwest China. PLoS ONE 2014, 9, 1-11. [CrossRef] [PubMed]

64. Hejazi, A.; Bahrani, M.; Kazemeini, S. Yield and yield components of irrigated rapeseed-wheat rotation as influenced by crop residues and nitrogen levels in a reduced tillage method. Am. J. Agric. Environ. Sci. 2010, $8,502-507$.

65. Song, K.; Yang, J.; Xue, Y.; Lv, W.; Zheng, X.; Pan, J. Influence of tillage practices and straw incorporation on soil aggregates, organic carbon, and crop yields in a rice-wheat rotation system. Sci. Rep. 2016, 6. [CrossRef] [PubMed] 
66. Fusco, G.; Miglietta, P.P.; Porrini, D. How Drought Affects Agricultural Insurance Policies: The Case of Italy. J. Sustain. Dev. 2018, 11,1-13. [CrossRef]

67. De Leeuw, J.; Vrieling, A.; Shee, A.; Atzberger, C.; Hadgu, K.M.; Biradar, C.M.; Keah, H.; Turvey, C. The potential and uptake of remote sensing in insurance: A review. Remote Sens. 2014, 6, 10888-10912. [CrossRef]

(C) 2019 by the authors. Licensee MDPI, Basel, Switzerland. This article is an open access article distributed under the terms and conditions of the Creative Commons Attribution (CC BY) license (http://creativecommons.org/licenses/by/4.0/). 